into "nursing homes" in the community" if the term "community care" is to be more than piffle before the wind. ${ }^{20}$

We thank the nursing staff and social workers at Tooting Bec Hospital for the major part they played in carrying out the initial and follow-up censuses. Requests for reprints or for further information from this study and the questionnaire should be addressed to $\mathrm{Dr} \mathrm{T} \mathrm{H}$ Bewley, Tooting Bec Hospital, London SW 17 8BL.

\section{References}

${ }^{1}$ Bewley TH, Bland JM, Ilo M, Walch E, Willington G. Census of menta hospital patients and life expectancy of those unlikely to be discharged. Br Med F 1975;iv:671-5.

${ }^{2}$ Magnus RV. The new chronics. Br f Psychiatry 1967;113:555-6.

${ }^{3}$ Registrar General. Statistical review of England and Wales for the year 1968. Appendix 4. English life table No 12 (1960-2). London: HMSO, 1970.

4 Department of Health and Social Security. Statistical and research report series No 8. London: HMSO, 1974.

${ }^{5}$ Department of Health and Social Security. Hospital services for the mentally ill. London: DHSS, 1971. (HM(71)97.)

${ }^{6}$ Department of Health and Social Security. Services for mental illness related to old age. London: DHSS, 1972. (HM(72)71.)

7 Goldstone L. Unknowns and intangibles. Health and Social Services fournal 1980;90:285-8.
${ }^{8}$ Jones K. Integration or disintegration in the mental health services. Fournal of the Royal Society of Medicine 1979;72:640-8.

${ }^{9}$ Hawks D. Community care: an analysis of assumptions. $\mathrm{Br} \mathcal{F}$ Psychiatry $1975 ; 127: 276-85$

10 National Health Service. A hospital plan for England and Wales. Cmnd 1604. London: HMSO, 1962.

11 Fottrell E, Peermohamed R, Kothari R. Identification and definition of long-stay mental hospital population. $B r$ Med f 1975;iv:675-7.

12 Department of Health and Social Security. Better services for the mentally ill. London: HMSO, 1975.

13 Penrose LS. Mental disease and crime: outline of a comparative study of European statistics. Br $\mathcal{F}$ Med Psychol 1941;18:1-15.

14 Bennett D. The chronic psychiatric patient today. Fournal of the Royal Society of Medicine 1980;73:301-3.

15 Department of Health and Social Security and Welsh Office. Patients first: consultative paper on the structure and management of the National Health Service in England and Wales. London: HMSO, 1979.

16 Department of Health and Social Security. Hospital services: the future pattern of hospital provision in England. A consultative paper. London: DHSS, 1980

17 Department of Health and Social Security. Organisation and management problems of mental illness hospitals. London: DHSS, 1980.

18 Jenkin P. Speech to Royal College of Psychiatrists annual dinner. Bulletin of the Royal College of Psychiatrists 1980:179-81.

19 Early DF, Nicholas M. Two decades of change: Glenside Hospital Population Surveys 1960-80. Br Med f 1981;282:1446-9.

${ }^{20}$ Ashford D. The young visiters. London: Chatto and Windus, 1919.

(Accepted 7 August 1981)

\title{
Innovations in medical records in the United Kingdom
}

\author{
FRANCIS AVERY JONES
}

Good medical records help clinical decision-making in diagnosis and treatment. In addition they serve as the means of communication between the clinical teams treating the patient, both in hospital and in primary care; they play a key part in facilitating clinical and epidemiological research; they provide the history-taking discipline that plays an essential part in the education of medical students and junior doctors; they allow an assessment of the quality of medical care services; and they furnish the evidence which may be needed for medicolegal purposes.

The department of community health in the University of Nottingham Medical School was commissioned by the King Edward's Hospital Fund for London to study recent innovations in the keeping of medical records. This fund makes a continuing contribution to the efficiency and effectiveness of the NHS, concentrating particularly on the Cinderella aspects, one of which is medical records. The resultant report, The King's Fund Gazetteer on Medical Records, brings together the innovations and special studies at present in progress in primary care, hospital practice, and health service administration.

\section{Problem-orientated medical records system (POMR)}

The traditional standard pattern of medical history-taking was admirable while the focus of attention remained on diagnosis; the clinician had to be right even if there was no effective treatment. Today, the many effective treatments really make an impact on disease, and Weed was the first to realise that

Central Middlesex Hospital, London NW10

Sir FRANCIS AVERY JONES, MD, FRCP, consulting physician traditional medical records did not place sufficient emphasis on managing the patient and particularly on looking at the patient as a whole. He therefore put forward his "problem-oriented medical records system" (POMR). The ideas are simple and sensible, but the terminology can be irritating. Weed's "data base" is more structured than is traditional history taking, with more emphasis on the patient's life profile. The "problem list" not only contains medical problems but also includes background social problems. The third component is the drawing up of plans for each problem and, finally, the introduction of structured progress notes. In this form the notes provide continuity of care and make it much easier for one doctor to take over from another. They also encourage logical thought, and above all they provide an invaluable aide memoire for the doctor each time he sees the patient. All this needs more discipline and a little more time.

The Gazetteer gives the main centres where POMR has been introduced and the ways in which it has been modified. The introduction of POMR has been slow, with more progress in Scotland than in England. While it is important to identify all problems during the patient's stay in hospital, it is not necessary or indeed possible to deal with all the problems during that time, but they should be passed on clearly to the general practitioner. At Ninewells Hospital, Dundee, the prescription form for patients being discharged provides a space for a problem list to be written in by the houseman. The structured discharge summary has been widely accepted as a simple and logical way of transmitting information back to the family practitioner. The registrar or consultant who dictates such summaries is therefore motivated to encourage his junior staff to structure the records so as to facilitate the writing of the summary.

The department of medicine at Newcastle has implemented a form of POMR with the production of a useful summaries problem card for use in the continuing medical care in the outpatient department. For this purpose, the problem list 
created during the patient's inpatient stay is rewritten and typed on a special card, together with enough detail to make it unnecessary to produce notes at every visit. Rather less emphasis seems to be placed on the preparation of the data base. The stimulation of the introduction of flow sheets has been a real advance. In England one teaching hospital which has completely gone over to POMR is Guy's Hospital, and Professor Ian McColl has shown the considerable improvement in the standard of medical care which can result from its use.

\section{A4 size records}

In primary care the main debate has been related to the need to switch over from the "Lloyd George" envelope to A4-size notes. The advantage of the larger, A4 envelope is its ability to include unfolded reports and letters from the hospital and also the ease with which a whole variety of new sheets can be included. In St Thomas's Hospital Medical School Practice Teaching Unit the A4 folders include: (a) modification of the continuation pages that include a short list of important problems; $(b)$ a family tree format for recording the family and social history; and $(c)$ patient self-administered questionnaires. A considerable number of practices in different parts of the country have been concerned with the innovation in primary care records. Another variation introduced at Aldeburgh in Suffolk is to use the A4 record folder to allow letters and reports to lie flat but to continue clinical reporting on the EC6/7 cards. At Abbots Langley in Hertfordshire the original Lloyd George EC6/7 envelope is used but forms have been devised on a folder sheet to fit the envelope. The continuation notes are problem orientated, and ruthless pruning is undertaken to avoid duplication. The experience of this and other practices shows that the Lloyd George envelope can be used effectively-but that considerable obsessional characteristics are needed for its success. Ingenuity is clearly being used to achieve diagnostic registers and to provide special practice information systems. Much is being done with simple card techniques, and now interest is veering towards the use of minicomputers. In a few places maximum use is already being made of computers, but keeping the medical record on tape presents many problems, and it seems probable that the computer will be used mainly as an adjunct to the notes, providing indexing and informationretrieval services.

\section{Use of computers}

Another developing field is linking an area health authority computer with practices, and at Oxford this is already highly developed and printouts of patient populations may be ordered by age and sex and even by geographical area or street and postal code. This is of help when taking on new patients, organising visitors, and to health visitors. Other services available include patient recall systems for immunisation, cervical cytology, hypertension, and diabetes.

Other aspects recorded include the Mickie computer-based interviewing system currently being evaluated by the DHSS. The friendly and logical branching of the computer interview and the many questions asked seem not only to make the patient feel at ease but to enhance the value of the subsequent face-toface confrontation with the doctor. It also allows the doctor to concentrate immediately on a particular problem and thus to make more effective use of his time. There has been some evidence that patients are more truthful when answering a computer than they are when questioned by the doctor. ${ }^{1}$

Much thought has been given to special forms-for instance, for obstetrics, diabetes, emergencies, and prescription sheetsand there are interesting experiments on shared records which can link hospital work and the general practitioner with the notes being kept by the patient. This was first pioneered by St Mary's Maternity Hospital, Portsmouth, where there was a great saving of overall time in the finding and refiling of notes and in the audiotyping of letters to general practitioners. Out of the first 12000 records carried by patients only four had been irretrievably lost—one eaten by a dog!

\section{Tunbridge Committee}

Credit should go to the DHSS for all the work which has flowed from the Tunbridge Committee on Standardisation of Medical Records. Against this, however, is the Department's failure to recognise the special responsibilities of medical records officers and to regard them as just one part of the administrative hierarchy. In hospitals, indeed in health districts, the records department is the hub of the hospital clinical activities. Both routine and research work and a well-run health service need a first-class organisation. The medical records officer has a responsible task, needing a strong sense of vocation and much skill. The further reorganisation of the NHS pinpoints the urgent need for information services to be strengthened in districts and regions. The time is even more opportune for medical records and information officers to be given a career structure, together with adequate facilities for special training in the early stages of their career and for special facilities to be provided for post-qualifications and academic experience leading to a university diploma.

The time is equally opportune for the medical profession, through their royal colleges, to recognise the importance of medical records specially designed for team work in providing good medical care both by general practitioners and by hospital staff. Enough preliminary work ${ }^{2}{ }^{3}$ has already been done for small working parties to make recommendations, which could then go from the colleges to the DHSS. The history of medical records shows that the time has now come for action and not further debate.

\section{References}

${ }^{1}$ Rector AL, Medcalf DHH, Clayden AD, Hallan L. Innovations in medical records in the UK. London: King's Fund Centre, 1980.

2 Tait I. History of our records. Br Med f $1981 ; 282: 702-3$.

3 Jones FA. Trends in medical records. Community Health 1975;7:32-48. (Harben lecture.)

(Accepted 26 August 1981)

For patients requiring antibiotic cover for dentistry work what degree of trauma is relevant? Does dental scaling or using a toothpick count as possible trauma? Should such patients be treated with antibiotics when they suffer a graze or thorn prick? Does bacteraemia result from invasion through the lymphatics of the gums or only through the blood vessels?

To arrive at an approach to dental prophylaxis that is in any way practical and therefore likely to be implemented certain assumptions have to be made, such as that the portal of entry of bacteria into the blood stream during dental procedures is through the blood vessels. For this reason those procedures likely to cause bleeding, such as fillings at the gum margin and scaling, as well as extraction, should receive antibiotic cover. ${ }^{1}$ Patients with cardiac disease should be warned against the vigorous use of toothpicks, for which antibiotic cover would be impracticable. In a somewhat different way unpredictable minor skin abrasions could not be covered, either, because of the great variety of organisms that they might introduce, but the number of organisms would be unlikely to be large and antibiotics are quite unnecessary for superficial skin damage. Worst of all, since trauma cannot be anticipated, antibiotics given after wounding would have missed the time of maximum bacteraemia anyway.-J H DARRELL, reader in clinical bacteriology, and CELIA OAKLEY, consultant cardiologist, Hammersmith.

${ }^{1}$ American Heart Association Committee. Prevention of bacterial endocarditis. Circulation 1977;56:139A-43A. 